\title{
Atypical proliferative Brenner tumour of the ovary with liver metastases: a case report
}

\author{
Saaliha Vali ${ }^{1 *}$, Mohamed Oumar ${ }^{2}$, Shefali Chavhan ${ }^{3}$, Olga Wise ${ }^{4}$, Ahmed Sayasneh ${ }^{5,6,7}$
}

\begin{abstract}
${ }^{1}$ Specialty Trainee in Obstetrics and Gynaecology, Department of Gynaecological Oncology, Guys and St Thomas' Hospital, London, UK

${ }^{2}$ Student, School of Medical Education, Faculty of Life Sciences and Medicine, King's College London

${ }^{3}$ Student, Department of Gynaecological Oncology, Guys and St Thomas' Hospital, London, UK

${ }^{4}$ Consultant Histopathologist. Department of Histopathology, Guys and St Thomas' Hospital, London, UK

${ }^{5}$ Consultant Gynae Oncologist. Department of Gynaecological Oncology, Guys and St Thomas' Hospital, London, UK

${ }^{6}$ School of Medical Education, Faculty of Life Sciences and Medicine, King's College London

${ }^{7}$ Department of Women and Children Health, School of Life Course Sciences, Faculty of Life Sciences and Medicine, King's College London
\end{abstract}

Received: 15 August 2019

Accepted: 30 September 2019

\section{*Correspondence:}

Dr. Saaliha Vali,

E-mail: saalihavali@gmail.com

Copyright: $\odot$ the author(s), publisher and licensee Medip Academy. This is an open-access article distributed under the terms of the Creative Commons Attribution Non-Commercial License, which permits unrestricted non-commercial use, distribution, and reproduction in any medium, provided the original work is properly cited.

\begin{abstract}
Brenners tumours constitute up to $2 \%$ of ovarian neoplasms. Most are benign with a gross fibroma like appearance. Here we present the case of a 45 year old woman who underwent a full staging laparotomy for a suspicious left ovarian mass. A $30 \mathrm{~cm}$ left ovarian cyst was found with no enlarged lymph nodes. Histologically this was a proliferative Brenner tumour. Postoperatively, a mild increase in the Ca125 prompted an MRI scan which revealed a $3 \mathrm{~cm}$ liver cyst. This was resected and histologically found to be a transitional cell carcinoma. Successful treatment with secondary excision and adjuvant chemotherapy has ensured disease free remission to date.
\end{abstract}

Keywords: Brenners, Ca125, Liver, Neoplasm, Ovarian, Tumour

\section{INTRODUCTION}

The Brenner tumour was first characterised in 1907 by German pathologist Dr Fritz Brenner. ${ }^{1}$ Ovarian Brenner tumours are rare adenocarcinomas, often unilateral and account for up to $2 \%$ of all ovarian neoplasms. Their size varies at presentation from less than $1 \mathrm{~cm}$ to up to $30 \mathrm{~cm}$. More than two thirds of patients present over the age of forty, with the average age being fifty. ${ }^{2}$

There is overall consensus of the tumour being derived from the ovarian surface epithelium through transitional cell metaplasia. Other theories propose a tubal origin through transitional metaplasia near the tuboperitoneal junction. $^{3}$ Histologically they appear to consist of urothelial cell nests surrounded by dense fibrous stroma consisting of oval nuclei with longitudinal grooving giving a characteristic coffee bean-shaped appearance. ${ }^{4,5}$

Mostly benign, up to $5 \%$ of Brenners tumours are proliferating or borderline. ${ }^{6}$ The proliferative Brenner was first described in 1971 as an intermediate neoplasm between the typical Brenner tumour and its malignant counterpart.

Proliferating Brenner epithelium resembles low grade papillary transitional cell carcinoma of the bladder. Extraovarian Brenner tumours are also rare, with few reports citing the vagina, uterus, broad ligament, omentum and testicular areas. ${ }^{8-10}$ 


\section{CASE REPORT}

The patient is a 45-year-old medically fit lady who presented to the colorectal team with painful rectal polyps which prompted CT imaging. This found an incidental complex left ovarian mass measuring 19x6 cm. There was no other evidence of local disease except for small volume enlargement of the left common ileac lymph node - the nature of which was unsure. CT imaging of the chest was also performed and was normal.

The imaging was reviewed at the Gynaecological Oncology MDT and the left ovarian mass was deemed likely to be malignant. She was asymptomatic of the mass, with no bowel symptoms, no abdominal pain nor any weight loss nor gain. Ca 125 level at initial presentation was 39, CEA 1.9 .

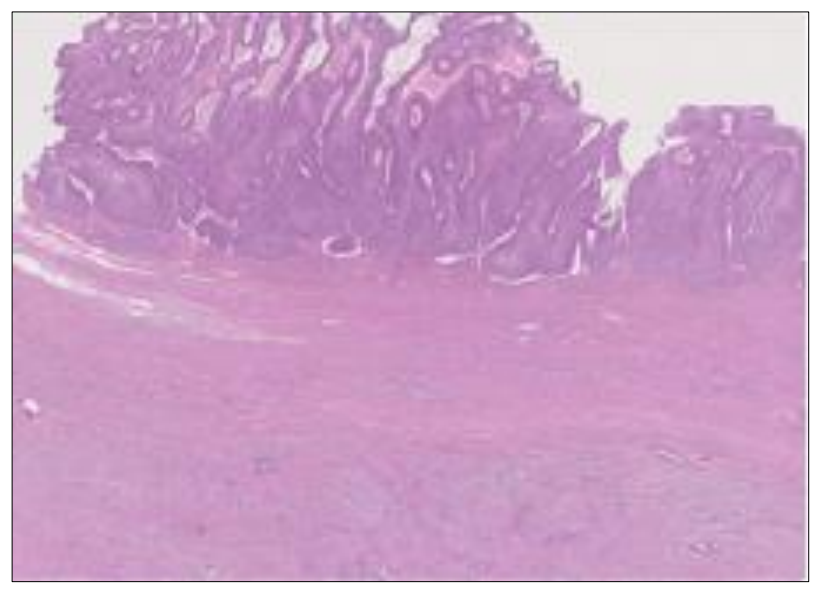

Figure 1: Ovarian tumour cells ( $\mathrm{H}$ and $\mathrm{E}$ stain) arranged in broad papillary structures.

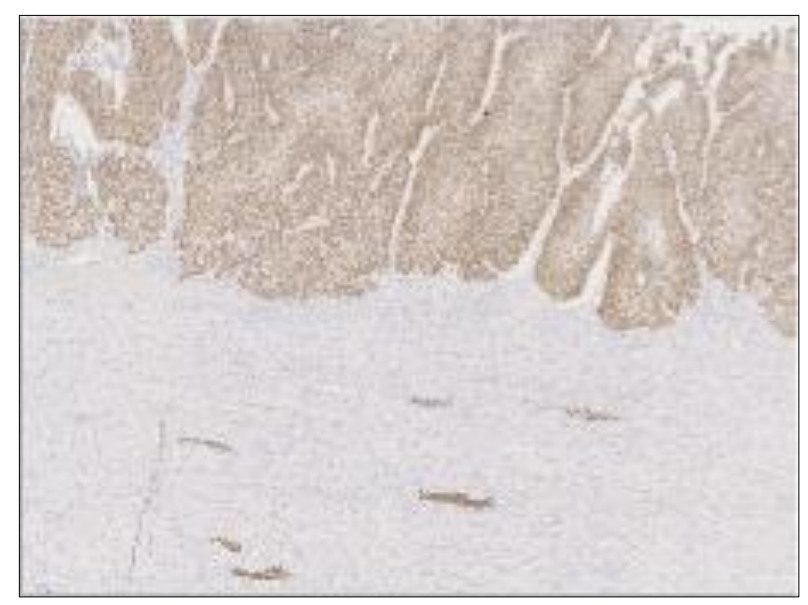

Figure 2: Ovarian tumour Immunohistochemistry staining positive for CK7, p63 and CK5.

The patient consented to a full staging laparotomy. A midline laparotomy, total abdominal hysterectomy, bilateral salpingo-oophorectomy, bilateral pelvic and para- aortic lymph node dissection and omentectomy was performed. The procedure was uncomplicated, and the patient recovered well. At surgery, a $30 \mathrm{~cm}$ left ovarian mass was removed, separate to the left ovary. The right ovary appeared normal and there were no grossly enlarged lymph nodes and no upper abdominal; disease. The bowels, omentum, liver peritoneum and omentum also appeared grossly normal. Histologically a diagnosis of a stage 1A borderline Brenner tumour of the left ovary was made (Figure 1), with no capsular surface involvement. All lymph nodes were benign and peritoneal washings clear. Immunohistochemistry revealed the tumour was ER and PR receptor negative (Figure 2, 3). The rectal polys were also resected and were benign fibroepithelial polyps.

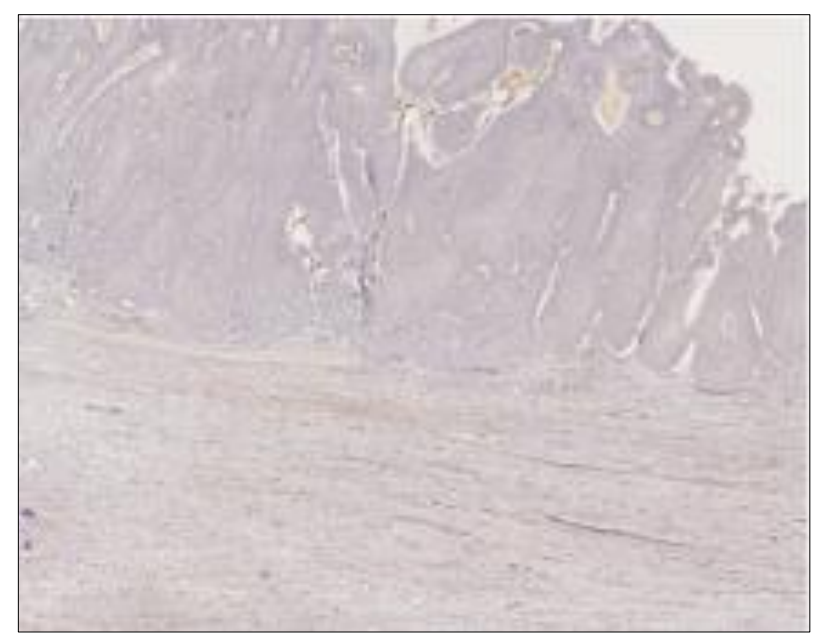

Figure 3: Ovarian tumour Immunohistochemistry staining negative for p16, ER, PR, CK20 and WT1.

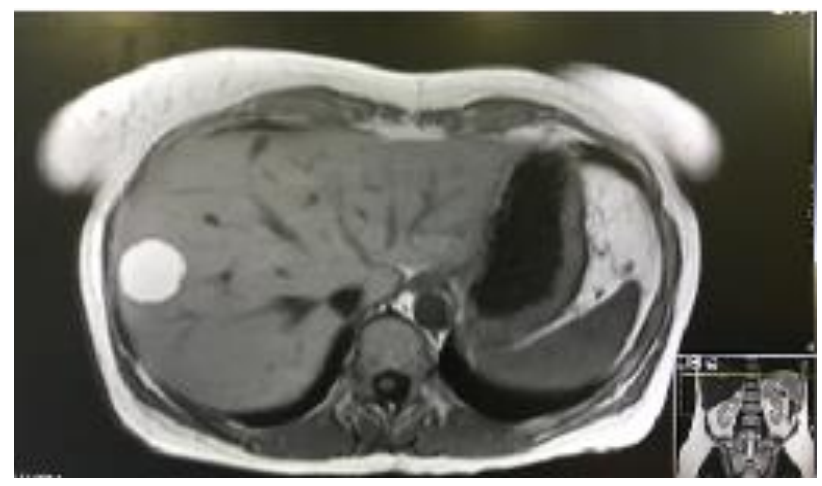

Figure 4: MRI image displaying liver lesion.

During a follow up appointment at six months post op, the patient reported very mild abdominal pain. In addition, a slightly elevated Ca125 of 39 prompted a MRI scan of the abdomen and pelvis. This revealed a new 3.1 $\mathrm{cm}$ liver cyst on the periphery of hepatic segment eight and appeared mildly irregular with contoured thin walls (Figure 4). There were no other suspicious findings. The case was referred to the regional liver unit and a partial hepatectomy was performed. Histologically the liver cyst was identifiable as metastasis of the Brenner tumour (Figure 5, 6). Following this, the patient had four cycles 
of adjacent chemotherapy with Carboplatin and Gemcitabine.

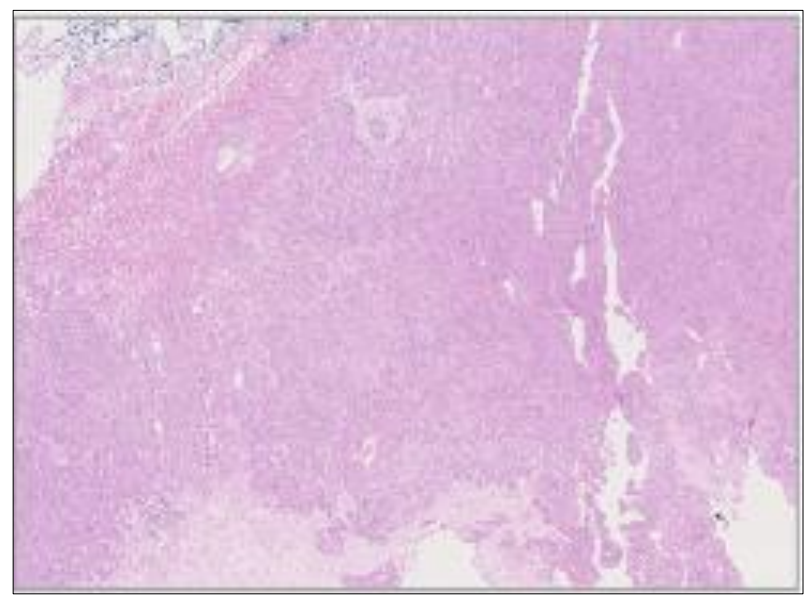

Figure 5: Liver tumour cells (H and E stain).

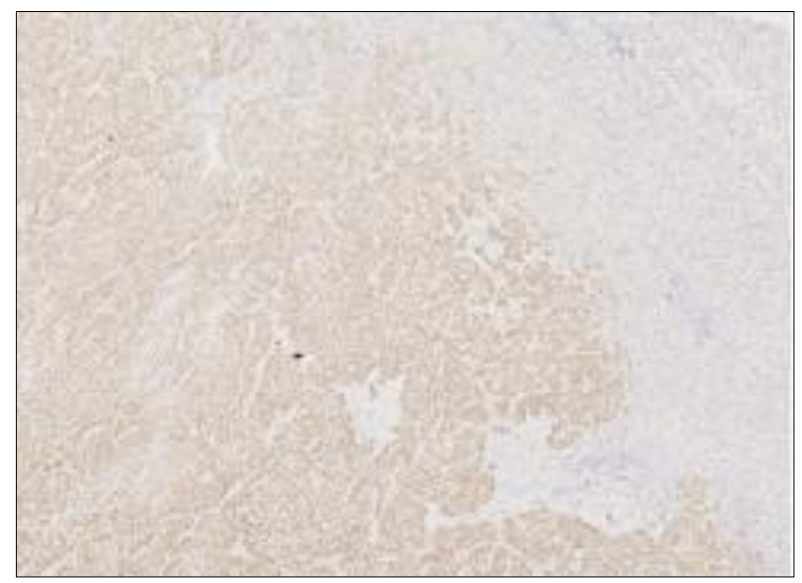

Figure 6: Liver tumour

immunohistochemistry staining.

\section{Pathologic findings}

\section{Gross description}

The resected tissue was an ovarian cystic mass, $23 \mathrm{~cm}$ in diameter with papillary masses projecting into the cyst lumen with an adjacent firm solid area $8 \mathrm{~cm}$.

\section{Microscopic description}

\section{Ovarian tumour}

The ovarian tumour demonstrated a cellular neoplasm, composed of proliferation of epithelial cells, resembling transitional (urothelial) cells. The cells were arranged in expansile broad papillary structures and displayed mild to moderate cytological atypia with increased mitotic activity. There was associated benign Brenner tumour component (Figure 1).
Unequivocal stromal invasion was not identified, and a diagnosis of Borderline Brenner tumour/atypical proliferative Brenner was made.

On immunohistochemistry, the tumour expressed CK7, p63 and CK5, but was negative for p16, ER, PR, CK20 and WT1 (Figures 2 and 3).

There was no involvement of the capsular surface or other structures (uterus, cervix, fallopian tubes, omentum, appendix, pelvic and para-aortic lymph nodes all clear).

\section{Liver tumour}

The liver tumour demonstrated a predominantly solid pattern with irregular nests and islands at the edges (Figure 4). The neoplastic cells morphologically resembled transitional cells.

The immunohistochemical profile was similar to that seen in the ovarian tumour (Figure 5). CK 7 (+), synaptophysin (-), chromogranin (-), CD 56 (-), CK 20 (), p63 (+), CK 5 (focally +), WT 1 (-), p16 (-), ER (focal weak +$)$, PR (-), PAX $8(-)$. The MIB 1 proliferative index is approximately $50-60 \%$.

The features were regarded those of a metastatic transitional cell carcinoma. and although this was considered a possible differential diagnosis, no primary urinary tract tumour was found on imaging. ${ }^{11}$

\section{Clinical outcome}

A follow up CTAP post adjacent chemotherapy showed no residual disease. The patient continues to remain well and has been started on hormone replacement therapy (Estradiol).

\section{DISCUSSION}

There are few reports in the literature of hepatic metastases from primary Brenner tumours. In one study, four patients developed hepatic metastases and the one remaining case suffered pulmonary and cerebral metastases. $^{12}$

Most Brenner tumours are benign with only 2-5\% being malignant. ${ }^{13}$ The mortality rate has been reported at about $50 \%$ with a mean survival time of one year. ${ }^{12,14}$ A large cohort study of over 200 patients found malignant Brenner tumours with extra ovarian spread held a five year disease free survival of $51.3 \% .^{15}$

Histologically these tumours display heterogeneous epithelial cell growth and atypia, comprising of transitional, squamous, undifferentiated or a mixture of cell types. Due to the varying histology, it has proven challenging to clarify an appropriate tumour marker for malignant Brenner tumours. ${ }^{16}$ CA125 is elevated in 30 $70 \%$ of patients with malignant Brenner tumours but 
values were not correlative to stage or tumour burden. ${ }^{15,17}$ Given its widespread use as a serologic marker in patients with epithelial ovarian cancers, it has been proposed to be used as a marker of reoccurrence in Brenner tumours displaying malignant characteristics. ${ }^{11}$

Imaging alone has proved to be a poor modality to determine if a mass is a Brenner tumour. One retrospective study of 29 Brenner tumours discovered incidentally after adnexal masses of unknown aetiology were removed failed to identify any ultrasound features specific to Brenner tumours. ${ }^{18}$ However another retrospective study utilising $\mathrm{CT}$ and $\mathrm{MRI}$ reported extensive amorphous calcification in a solid component within a multilocular cystic mass is a characteristic finding of Brenner tumor of the ovary. ${ }^{19}$

Surgery remains the mainstay of treatment for Brenner tumours. A large retrospective population-based analysis of patients with malignant Brenner tumours found $98 \%$ were treated with primary surgery. ${ }^{15}$ Interestingly, pelvic and para-aortic lymph node dissection so often performed for accurate staging in ovarian tumours did not render any disease-free survival benefit for this cohort. Therefore, the necessity of a complete staging procedure in this group has yet to be determined, but is currently recommended by the International Federation of Gynaecology and Obstetrics (FIGO).$^{20}$ Sensitivity at frozen section is to be evaluated and its use in this context would allow for the extent of the operation to be revised, potentially reducing the operative morbidity.

The main differential for malignant Brenner tumour of the ovary remains TCC. However, on gross examination TCC lacks the calcifications often seen in the malignant Brenner tumour. ${ }^{21}$ On immunochemistry TCC's display p53 mutations with p53 and p16 protein overexpression in contrast to the malignant Brenner, which has been found to be negative for both but strongly positive for Cyclin D1, Ras, and EGFR. TCCs have shown negative immunoreactions to Cyclin D1, Ras, and EGFR. Results from a small-scale study suggest malignant Brenner tumours and TCC's follow distinctly different tumorigenic pathways. ${ }^{22}$

One early study found malignant Brenner tumour of the ovary was likely to present earlier than TCC $(69 \%$ versus $19 \%$ ) and was less aggressive irrespective of tumour stage. $^{21}$

\section{CONCLUSION}

Here we describe a case of malignant Brenner tumour of the ovary with atypical hepatic spread successfully treated with surgery and adjuvant chemotherapy. Secondary excision and chemotherapy have been successful in inducing remission with the patient remaining disease free at twelve months. The case is consistent with findings in the literature but highlights the need for extensive work up and strong consideration given to $\mathrm{Ca} 125$ as a marker of recurrence.

Funding: No funding sources

Conflict of interest: None declared

Ethical approval: Not required

\section{REFERENCES}

1. Brenner F. Ds oophoroma folliculare. Frankf $Z$ Pathol. 1907;1:150-71.

2. Hemalatha AL, Konanahalli P. Bilateral malignant Brenner tumor of ovary. J Obstet Gynecol India. 2005;55:81-2.

3. Kuhn E, Ayhan A, Shih IeM, Seidman JD, Kurman RJ. Ovarian Brenner tumour: a morphologic and immunohistochemical analysis suggesting an origin from fallopian tube epithelium. Eur $\mathbf{J}$ Cancer. 2013;49:3839-49.

4. Roma AA, Masand RP. Ovarian Brenner tumors and Walthard nests: a histologic and immunohistochemical study. Hum Pathol. 2014;45:2417-22.

5. Riedel I, Czernobilsky B, Lifschitz-Mercer B, Roth LM, Wu XR, Sun TT, et al. Brenner tumors but not transitional cell carcinomas of the ovary show urothelial differentiation: immunohistochemical staining of urothelial markers, including cytokeratins and uroplakins. Virchows Arch. 2001;438:181-91.

6. Hallgrìmsson J, Scully RE. Borderline and malignant Brenner tumours of the ovary. A report of 15 cases. Acta Pathol Microbiol Scand Suppl. 1972;233:56-66.

7. Roth LM, Sternberg WH. Proliferating Brenner tumors. Cancer. 1971;27:687-93.

8. Shaco-Levy R, Benharroch D. Vaginal Brenner tumor. Int J Gynecol Pathol. 2013;32:238-41.

9. Robinson TG. Extraovarian Brenner tumor. J Obstet Gynaecol Br Emp. 1950;57:890-1.

10. Quan J, Jin L, Hu J, He T, Pan X, Ding Y, et al. Brenner tumor of the testis: a case report and review of the literature. Mol Clin Oncol. 2017;6:119-21.

11. Lang SM, Mills AM, Cantrell LA. Malignant Brenner tumor of the ovary: review and case report. Gynecol Oncol Rep. 2017;22:26-31.

12. Yue Z, Si T, Pan Z, Cao W, Yan Z, Jiang Z et al. Malignant Brenner tumor of the ovary: clinical, pathological and demographic analyses of 10 cases. Int J Clin Exp Pathol. 2016;9:5642-6.

13. Yamamoto R, Fujita M, Kuwabara M, Sogame M, Ebina Y, Sakuragi N, et al. Malignant Brenner tumors of the ovary and tumor markers: case reports. Jpn J Clin Oncol. 1999;29:308-13.

14. Ben Aissia N, Sadfi A, Youssef A, El Ayeb A, Chadli A, Mzabi R, et al. Malign Brenner's tumor particularities and coverage. Tunis Med. 2004;82:701-7.

15. Nasioudis D, Sisti G, Holcomb K, Kanninen T, Witkin SS. Malignant Brenner tumors of the ovary; a population-based analysis. Gynecol Oncol. 2016;142:44-9. 
16. Riedel I, Czernobilsky B, Lifschitz-Mercer B, Roth LM, Wu XR, Sun TT, et al. Brenner tumors but not transitional cell carcinomas of the ovary show urothelial differentiation: immunohistochemical staining of urothelial markers, including cytokeratins and uroplakins. Virchows Arch. 2001;438(2):181-91.

17. Han JH, Kim DY, Lee SW, Park JY, Kim JH, Kim $\mathrm{YM}$, et al. Intensive systemic chemotherapy is effective against recurrent malignant Brenner tumor of the ovary: an analysis of 10 cases within a single center. Taiwan J Obstet Gynecol. 2015;54:178-82.

18. Dierickx I, Valentin L, Van Holsbeke C, Jacomen G, Lissoni AA, Licameli A, et al. Imaging in gynecological disease: clinical and ultrasound features of Brenner tumors of the ovary. Ultrasound Obstet Gynecol. 2012;40:706-13.

19. Takahama J, Ascher SM, Hirohashi S, Takewa M, Ito $\mathrm{T}$, Iwasaki $\mathrm{S}$, et al. Borderline Brenner tumor of the ovary: MRI findings. Abdom Imaging. 2004;29:528-30.

20. Heintz AP, Odicino F, Maisonneuve P, Quinn M.A, Benedet JL, Creasman WT, et al. Carcinoma of the ovary. FIGO $26^{\text {th }}$ annual report on the results of treatment in gynecological cancer. Int J Gynaecol Obstet. 2006;95:161-92.

21. Austin RM, Norris HJ. Malignant Brenner tumor and transitional cell carcinoma of the ovary: a comparison. Int J Gynecol Pathol. 1987;6:29-39.

22. Cuatrecasas M, Catasus L, Palacios J, Prat J. Transitional cell tumors of the ovary: a comparative clinicopathologic, immunohistochemical, and molecular genetic analysis of Brenner tumors and transitional cell carcinomas. Am J Surg Pathol. 2009;33:556-67.

Cite this article as: Vali S, Oumar M, Chavhan S, Wise O, Sayasneh A. Atypical proliferative Brenner tumour of the ovary with liver metastases: a case report. Int J Reprod Contracept Obstet Gynecol 2019;8:4576-80. 